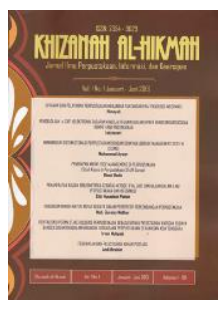

\title{
TREN PERKEMBANGAN OPEN ACCESS INSTITUTIONAL REPOSITORY PADA PERGURUAN TINGGI DI INDONESIA
}

\author{
Chusnul Chatimah Asmad, Taufiq Mathar, A. Khaidir Akbar, Nur \\ Arifin, Hijrana, Haruddin, Irmawati, Irawati, Satriani
}

Pengutipan: Asmad, C. C., Mathar, T., Akbar, A. K., Arifin, N., Hijrana., Haruddin., Irmawati., Irawati., Satriani. (2018). Tren perkembangan open access institutional repository pada perguruan tinggi di Indonesia . Khizanah al-Hikmah : Jurnal Ilmu Perpustakaan, Informasi, dan Kearsipan. 6(2), 168-180.

DOI: https://doi.org/10.24252/kah.v6i2a8

*Dosen Jurusan Ilmu Perpustakaan UIN Alauddin Makassar

Email korespondensi:, taufiq.m@uin-alauddin.ac.id

\section{ABSTRAK}

Open Access (OA) atau akses terbuka dapat menjadi jalan alternatif dalam menyebarkan informasi ilmiah kepada seluruh dunia tanpa dibatasi ruang dan waktu. Repositori institusi atau instutional repository (IR) telah banyak diaplikasikan pada beberapa perguruan tinggi di Indonesia. Tulisan ini mendeskripsikan pemetaan perkembangan repositori institusi perguruan tinggi di Indonesia yang open akses dan perangkat lunak yang digunakannya pada portal OpenDOAR. Penelitian ini terbatas pada repositori institusi perguruan tinggi yang telah terdaftar di OpenDoar saja. Hasil penelitian menunjukkan bahwa terdapat peningkatan jumlah perkembangan repositori di Indonesia pada OpenDOAR mulai dari tahun 2008 hingga 2018 ini. Sementara perangkat lunak yang digunakan ialah Eprints, Dspace, dan lainnya.

Kata kunci: Repositori institusi; akses terbuka

\section{ABSTRACT}

Open Access (OA) can be an alternative way of disseminating scientific information to the globe without limited by space and time. Institutional repositories (IR) have been widely applied to several universities in Indonesia. This paper describes the mapping of the development of open access institutional universities in Indonesia and the software used from the OpenDOAR website. This research is limited to the repository of tertiary institutions that have been registered in OpenDoar only. The results showed that there was an increase in the number of repository developments in Indonesia in OpenDOAR starting from 2008 to 2018. While the software used is Eprints, Dspace, and others.

Keywords: Institutional repository; open access

\section{PENDAHULUAN}

Open Access (OA) atau akses terbuka merupakan jalan alternatif dalam menyebarkan informasi ilmiah kepada seluruh dunia tanpa dibatasi ruang dan waktu. OA berarti pembukaan akses informasi online maupun digital tanpa memerlukan biaya dan izin terlebih dahulu kepada penerbit rujukan ilmiah yang ingin diunduh. OA dapat berlaku bagi jurnal maupun karya tulis mahasiswa, dosen ataupun staf Perguruan Tinggi. 
Apabila sifatnya literatur kelabu, maka wadah yang menampungnya disebut Repositori Institusi (Institutional Repository).Saat ini, eksistensi repositori atau lebih akrab dikenal sebagai Instutional Repository atau IR telah banyak diaplikasikan pada beberapa perguruan tinggi di Indonesia. Bahkan saat ini, sudah ada 68 repositori perguruan tinggi yang telah terdaftar di OpenDOAR. Jumlah yang banyak tidak menjadi tolak ukur banyaknya repositori dalam negeri bahkan menjadi tren setiap daerah di Nusantara. Perkembangannya sangat pesat, meski repositori tersebut masih banyak yang belum terdaftar di OpenDOAR.

Aktivitas Ilmiah atau komunikasi ilmiah melalui repositori di atas terwujud dikarenakan adanya Undang-undang atau Peraturan Pemerintah terkait Publikasi ilmiah dan penelitian seperti Undangundang No 20 Tahun 2003 tentang Sistem Pendidikan Nasional, Undang-undang No 14 Tahun 2015 tentang Guru dan Dosen, Permen Ristekdikti No 20 Tahun 2017 tentang Pemberian Tunjangan Profesi Dosen dan Tunjangan Kehormatan Professor, Permen Agama RI No 55 Tahun 2014 tentang Penelitian dan Pengabdian kepada Masyarakat pada Perguruan Tinggi Keagamaan.

Repositori dapat memudahkan peneliti manapun untuk mengakses informasi penelitian terdahulu yang memiliki kesamaan fokus dan ruang lingkup dengan penelitiannya. Selain itu, repositori juga dapat menjadi filter munculnya duplikasi ilmiah dikalangan civitas akademika dan menjadi mediasi alih produk intelektual melalui knowledge management. Inilah yang menjadi alasan bagi perguruan tinggi untuk berlombalomba dalam membuat repositori dan menjadi sebuah tren yang patut diteliti.
Dalam sejarah penelitian di Indonesia, subjek repositori telah banyak dipublikasikan, khususnya penelitian yang melibatkan seluruh repositori yang terdaftar di OpenDOAR seperti yang telah dilakukan Farida et al (2015) dengan judul "A Concept Perguruan Tinggi Model of Open Access Instutional Repository in Indonesia Academic Libraries: Viewed from Knowledge Management Perspective", namun demikian penelitian ini hanya melibatkan 35 entri repository, sementara saat ini jumlah repositori yang terdaftar di OpenDOAR sebanyak 68 entri.

Sementara jumlah Perguruan Tinggi berdasarkan Pangkalan Data Perguruan Tinggi Kementerian Riset dan Teknologi sebanyak 4.460 perguruan Tinggi. Sehingga penelitian tersebut perlu dikembangkan melalui development research dengan konsep dan metode penelitian yang berbeda dan berfokus untuk melihat tren open access Institutional Repository atau OAIR di Indonesia. Melalui penelitian ini, dampak perkembangan repositori di perguruan tinggi Indonesia terhadap komunikasi ilmiah dapat dilihat secara langsung dan akhirnya dapat berkontribusi dalam pengambilan keputusan terkait kebijakan open access Repositori Institusi di Indonesia.

Latar belakang yang telah dipaparkan di atas melahirkan beberapa pokok permasalahan dalam penelitian ini dan dirumuskan dalam beberapa poin yaitu 1) Bagaimana tren perkembangan OAIR pada Perguruan Tinggi di Indonesia, 2) Bagaimana pemetaan perkembangan OAIR pada Perguruan Tinggi di Indonesia berdasarkan lokasi geografis, dan perangkat lunak (software) apa yang digunakan oleh Perguruan Tinggi pada repositori. 
Secara umum, tujuan penelitian ini telah disebutkan pada latar belakang di atas, akan tetapi secara rinci tujuan perencanaan penelitian dan ouput hasil penelitian ini adalah untuk mengetahui tren perkembangan OAIR pada Perguruan Tinggi di Indonesia, untuk mengetahui pemetaan perkemetaan perkembangan OAIR pada Perguruan Tinggi di Indonesia berdasarkan lokasi, dan untuk mengetahui software atau perangkat lunak yang digunakan oleh Perguruan Tinggi dalam membangun repositori

\section{KAJIAN PUSTAKA}

\section{a. Open Access (Akses Terbuka)}

Open Access (OA) dapat diartikan sebagai cara untuk mengakses ataupun membuat konten digital yang memiliki kebebasan hak cipta maupun tidak dan tanpa adanya batas lisensi serta bebas biaya demi keperluan keilmuan (Ghosh and Kumar Das 2007: 231). Sebagaimana yang telah disepakati dunia akademik, secara global kebebasan akses informasi sangat dilegalkan jika tujuannya bersifat ilmiah bukan komersial. Selain itu, banyak penelitian yang dibiayai oleh pemeritah terutama dalam proyek hibah penelitian seharusnya dapat dipastikan telah disebarluskan melalui internet tanpa adanya batasan-batasan tertentu. Itulah sebabnya gerakan OA dan Open Archives Initiative (OAI) terus meningkat terutama dalam tiga dekade terakhir ini dengan tujuan visibilitas dan penyebaran data intelektual ke seluruh dunia (Zaki and Dollah 2012:427).

Pada mulanya, inisiatif OA ini pertama kali dilaksanakan di Budapest pada Tahun 2001 dengan tujuan untuk melakukan reformasi sistem komunikasi ilmiah yang telah ada sebelumnya. Inisiatif ini akhirnya mendorong segenap civitas akademika maupun para ilmuwan dan sarjana untuk mempublikasikan artikel ilmiah mereka pada jurnal yang berbasis OA dan repositori berbasis OA. Harapan dari inisiatif OA ini tak lain agar seluruh masyarakat akademik di seluruh dunia dapat mengakses informasi ilmiah yang dibutuhkannya tanpa terhalang oleh masalah ekonomi (Yiotis 2005: 160).

Bagi Okoye \& Ejikeme (2011: 2), OA memiliki peran yang sangat penting, kontribusi yang besar, dan andil yang sangat besar dalam memudahkan para peneliti di Negara-negara bekembang untuk mengakses literatur-literatur ilmiah tanpa hambatan atau persyaratan khusus terlebih daulu. Meski demikian, tanpa kebijakan OA di perguran tinggi, terdapat direktori dan database yang memberikan free access seperti The Health Inter Network Access to Research Initiative (HINARI), Online Access to Research in the Invironment (OARE), Journal Storage, Jstor, Directory Open Access Journal (DOAJ), dan lain sebagainya. Hanya saja penyedia literatur ilmiah yang telah disebutkan ada yang tidak dapat diakses secara individu, sehingga perguruan tinggi harus melanggannya agar para peneliti dapat mengaksesnya secara bebas. Hal itupun dapat dilakukan jika peneliti tersebut berada dalam lokasi perguruan tinggi yang telah berlangganan.

Oleh sebab itu, OA sangat dibutuhkan dalam menumbuhkan dan mengembangkan aktivitas penelitian di negara berkembang khususnya di Indonesia. Banyak perguruan tinggi yang telah menerapkan hal tersebut, namun ada beberapa diantaranya salah mengerti hakikat dari OA yang sebenarnya. Sehingga dapat dikatakan, bahwa sebenarnya OA pada suatu perguruan tinggi yaitu peneliti, mahasiswa, dosen, staf perguruan tinggi, maupun masyarakat baik dalam maupun luar 
negeri dapat mengakses, menemukan kembali, mendistribusikan, mengunduh secara full-text literatur yang diinginkan, menyebarkan, mengutip karya ilmiah yang telah dipublikasikan secara bebas biaya, dengan ketentuan atau kebijakankebijakan tertentu dari masing-masing perguruan tinggi yang bersangkutan.

\section{b. Repositori Institusi (Intitusional Repository)}

Pada abad ke 21 saat ini, persaingan antar perguruan tinggi tidak hanya dinilai dari jumlah mahasiswa yang terdaftar ataupun jumlah alumni yang berhasil direkrut sebuah universitas, akan tetapi kualitas riset atau hasil penelitian yang dihasilkan mampu diakses di seluruh dunia khususnya dalam dunia akademik. Perguruan Tinggi yang besar maupun kecil memiliki posisi yang sama dalam mempublikasikan dan melestarikan karya intelektual civitas akademika masingmasing melalui alih media digital dengan membangun Repositori Institusi atau Institute Repository (IR) (Das \& Singh, 2017: 62-63)

Repositori institusi merupakan pangkalan data sekaligus layanan yang mengumpulkan, menyimpan, mengindeks, melestarikan, dan mendistribusikan hasil penelitian ilmiah perguruan tinggi dalam bentuk digital dan dapat diakses via online (Barton \& Waters, 2004:10). Proyek repositori pertama dalam dunia akademik dipelopori oleh EPrints di Southampton pada tahun 2001 yang sekarang dikenal dengan e-Prints Soton. Disusul kemudian oleh DSpace yang didirikan oleh MIT pada tahun 2002 yang menggunakan Open Access Initiative secara paralel. Dahulu, mayoritas pembangun repositori adalah negara-negara maju, namun seiring berjalannya waktu negara-negara berkembang pun ikut membangun repositori institusi yang pada umumnya berada di bawah naungan perpustakaan perguruan tinggi (Cullen and Chawner 2011:461).

Negara Kepulauan Indonesia sendiri yang memiliki banyak perguruan tinggi juga menjadikan pembangunan repository institusi sebagai tren dan kebanyakan diantaranya telah menggunakan e-Prints. Selanjutnya, berdasarkan hasil penelitian telah disebutkan bahwa pada umumnya konten repositori institusi perguruan tinggi di Indonesia berupa tugas akhir seperti tesis, disertasi, buku teks, buku modul, hasil penelitian dan proyek suatu komunitas, laporan layanan, laporan praktikum atau laporan Praktek Kerja Lapangan, makalah lokakarya/seminar, hasil paten, hasil penghargaan kompetisi pelajar untuk rangkin satu hingga ketiga di perguruan tinggi/regional/nasional/dan tingkat internasional (Farida et al. 2015: 175).

Repositori Institusi merupakan salah satu layanan yang diberikan perguruan tinggi kepada civitas akademika dalam rangka mengatur, mengorganisasikan, mengelola, dan menyebarkan karya ilmiah berbentuk elektronik yang berasal dari civitas akademika itu sendiri. Melalui IR, karya intelektual yang telah dihasilkan suatu penelitian dapat dikelola dengan baik, dilestarikan agar dapat digunakan dalam jangka waktu yang panjang, mendukung kegiatan administrasi perguruan tinggi, dan mudah diakses dan didistribusikan kepada dunia.

Penanggung jawab IR di Perguruan Tinggi berbeda satu sama lain. Namun IR akan lebih efektif berjalan apabila berada di bawah naungan Perpustakaan, Lembaga Pusat Teknologi Informasi, Kearsipan, Fakultas, Lembaga Penjaminan Mutu, Lembaga Penelitian dan Pengabdian, Tata Usaha perguruan tinggi, 
dan Pembuat Kebijakan. IR bukan hanya berupa perangkat lunak dan perangkat keras, akan tetapi seperangkat elemen teknologi informasi, unsur-unsur manajemen perubahan teknologi, dan berbagai jenis konten digital baik itu literatur kelabu maupun karya lainnya seperi Paten, Buku, Laporan Penelitian dan sebagainya (Lynch, 2003: 2)

Teori manajemen perusahaan selalu menyatakan "Right man in the right place". Namun dalam manajemen informasi yang ada adalah "right information in the right time, right information in the right decision, dan right information in the right act". Oleh karena itu, untuk mendapatkan informasi yang baik dan benar yang bermanfaat bagi kelangsungan hidup perguruan tinggi, maka pembangungan IR sebagai wadah penyimpanan informasi ilmiah di perguruan tinggi sangat dibutuhkan.

Apalagi IR bertindak sebagai elemen knowledge management dalam proses input output pengetahuan di perguruan tinggi, berisi informasi ilmiah dalam berbagai bentuk seperti artikel jurnal baik yang belum diterbitkan maupun yang telah dipublikasikan, makalah konferensi atau prosiding, buku dosen, dikat atau buku ajar lainnya, skripsi, tesis, laporan penelitian, studi kasus, penelitian survei, maupun data yang belum diolah sama sekali (Jain, 2011: 128).

\section{c. Open Access Institutional Repository (OAIR)}

Perpustakaan sebagai jantung perguruan tinggi tidak akan melepaskan diri dari kegiatan ilmiah, penelitian, dan informasi. Fungsi Perpustakaan perguruan tinggi sebagai penghubung atau mediasi penyebaran informasi karyakarya intelektual pada akademisi sangat dirasakan. Bukan hanya itu, perpustakaan perguruan tinggi berperan dalam mendukung dan memberikan fasilitas yang memperlancar kegiatan belajar mengajar fakultas, membantu penyelesaian penelitian maupun tugastugas, meningkatkan skill literasi informasi, menyediakan bantuan dan dukungan secara aktif agar kualitas karya ilmiah masyarakat akademik tetap terjaga produktivitasnya, memenuhi kebutuhan informasi civitas akademik dengan melanggan berbagai jurnal elektronik baik dalam maupun luar negeri, membangun repositori dengan tujuan untuk mengumpulkan, menyimpan, melestarikan dan menjaga keasilan karya intelektual yang ada, bertindak sebagai portal utama pencarian informasi sekaligus penerbit karya ilmiah yang dihasilkan civitas akademika dan menjadi kurator pengumpulan data yang dibutuhkan dalam penelitian, menyediakan fasilitas sistem temu kembali informasi yang mudah digunakan, sehingga para sivitas akademika semakin mudah mendapatkan rujukan ilmiah untuk memperlancar penelitiannya (American Library Association, 2012)

Tidak dapat dipungkiri karya-karya intelektual di beberapa perguruan tinggi negara berkembang seperti Indonesia memiliki kualitas yang tidak jauh berbeda dengan produk intelektual di negaranegara maju. Sehingga gerakan OAIR juga menjadi ajang kompetisi di Perguruan Tinggi dan juga mampu menjadi syarat Penerimaan Beasiswa oleh Perguruan Tinggi Negara maju yang diinginkan. Hanya saja, kesadaran dalam membangun OAIR di negara-negara berkembang masih rendah tidak seperti negara-negara maju pada umumnya yang telah mengakui manfaat besar OAIR yang ditandai dengan konversi materi tercetak ke digital untuk dipublikasikan secara OA semakin pesat. Hal ini juga dipengaruhi 
oleh citra perpustakaan yang masih dipandang sebagai status konvensinal (Islam \& Akter, 2013). Hal ini menjadi tantangan sekaligus peluang bagi Perpustakaan Perguruan Tinggi terutama di Indonesia.

Apabila Perguruan Tinggi masih lebih memilih closed access dibandingkan open access, maka hal itu akan membuat perguruan tinggi tersebut dipandang sebagai institusi yang tidak ingin berkontribusi secara besar-besaran terhadap perkembangan ilmu pengetahuan melalui penelitian. Masalah ini juga akan berdampak besar bagi karir pustakawan, di mana mereka sebagai role model atau senter utama dalam penelitian tidak akan terlihat (Narayan \& Luca, 2017).

Adanya OAIR di perguruan tinggi akan memperlihatkan kualitas karya ilmiah yang dimiliki perguruan tinggi tersebut, sehingga akan mengundang terjadinya kolaborasi dengan perguruan tinggi lainnya terlepas dari hambatan yang ada sehingga Insititutional Repository yang tadinya berbasis OA mampu menjadi Open Educational Resource (OER). Keberadaan OER ini akan membuat peran pustakawan semakin dibutuhkan, dikarenakan OAIR akan lebih efektif dikelola oleh pustakawan yang memiliki keahlian dalam menganalisis informasi, mengindeks, klasifikasi, diseminasi, dan retrieval (Leng, Ali, \& Hoo, 2016: 47).

\section{METODOLOGI PENELITIAN}

Penelitian ini adalah penelitian deskriptif dengan menggunakan pendekatan statistik. Dengan berusaha untuk menggambarkan tren perkembangan IR pada Perguruan Tinggi di Indonesia, penelitian ini akan menunjukkan statistika IR di Perguruan Tinggi dari masa ke masa. Dengan pendekatan ini nantinya akan dapat diprediksi ke depan perkembangannya. Tren perkembangan ini dapat dilihat pada situs OpenDOAR. Sebagai mana yang pernah juga dilakukan oleh peneliti terdahulu (Farida et al. 2015: 173).

Direktori OpenDOAR menyediakan list OAIR yang telah dijamin kualitasnya di seluruh dunia. Sebelum sebuah repositori terdaftar di OpenDOAR, staf direktori tersebut melihat perkembangan repositori yang telah mendaftarkan diri, melihat jenis metadata yang digunakan agar mempermudah kategorisasi repositori di OpenDOAR dan menganalisisnya agar repositori tersebut dapat digunakan dan diakses secara luas. Bahkan tak jarang Staf OpenDoar mengunjungi langsung suatu repositori untuk memastikan kompetensi dan kualitas informasi ilmiah yang dimiliki oleh repositori tersebut. OpenDOAR sendiri dikelola oleh Pusat Penelitian Komunikasi Universitas Nottingham berbasis layanan SHERPA. (OpenDOAR, 2013)

Saat ini, jumlah repositori yang terdaftar di OpenDOAR sebanyak 68 entri ROAR berjumlah 134 entri tanpa adanya spesisifkasi perangkat lunak. Data yang ada dalam OpenDOAR kemudian dipetakan berdasarkan item-item yang ditampilkan oleh direktori OAIR tersebut. Data-data yang telah diperoleh dari berbagai sumber di atas selanjutnya akan ditabulasi dengan bantuan Ms. Excel untuk memudahkan peneliti melihat tren perkembangan IR dari tahun ke tahun. Selain itu, juga akan menunjukkan letak geografis tiap-tiap IR tersebut. Dari sini, peneliti akan dapat mencoba memberika analisis prediksi perkembangan atau pertumbuhan IR di Indonesia. 
Chusnul Chatimah Asmad, Taufiq Mathar, A. Khaidir Akbar, Nur Arifin, Hijrana, Haruddin, Irmawati, Irawati, Satriani: Tren perkembangan Open Access Institutional Repository pada Perguruan Tinggi di Indonesia

\section{HASIL PENELITIAN DAN PEMBAHASAN \\ a. Tren Perkembangan OAIR pada Perguruan Tinggi di Indonesia}

1) Perkembangan Repositori Pertahun

Jumlah repositori tahun 2018 yang terdaftar di OpenDOAR saat ini adalah 70. Perkembangan yang sangat signifikan dari tahun ke tahun, di mana pada tahun 2008 hanya satu repositori yang terdaftar di OpenDOAR. Selanjutnya, range tingkatan jumlah repositori yang terdaftar berbentuk random, di mana pada tahun 2010 dan 2013 jumlah repositori yang terdaftar sebanyak 3, pada tahun 2018 sebanyak 6, pada tahun 2012 dan 2014 sebanyak 8, pada tahun 2017 sebanyak 9, pada tahun 2011 dan 2014 sebanyak 10. Meningkat pesat pada tahun 2016 sebanyak 12 . Meskipun naik turun, perkembangannya tidak tampak fluktuatif sebagaimana grafik Growth of OpenDOAR di bawah ini.

Banyaknya OAIR yang terdaftar di OpenDOAR pada tahun 2016 menunjukkan bahwa kesadaran perguruan tinggi terhadap manfaat OpenDOAR cukup tinggi di mana melalui OpenDOAR, setiap institusi dapat melakukan benchmarking terhadap repositori perguruan tinggi lainnya dan seluruh civitas akademik baik dalam maupun luar institusi mampu memanfaatkan repositori secara optimal terutama bagi para dosen dan mahasiswa.

Sementara itu, jumlah instansi yang membangun repositori pertahun perkembangannya juga sangat signifikan namun terjadi fluktuatif. Pembangunan repositori naik turun, meski pada tahun 2011-2013 giat perguruan tinggi patut diapresiasi dalam memahami pentingnya membangun OAIR. Selain itu, perkembangannya cukup memadai mulai dari tahun 2015-2017, di mana pada tahun

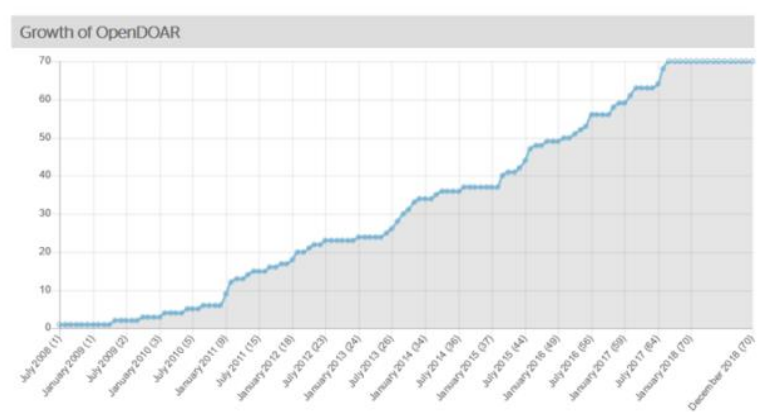

2015 terjadi pembangunan OAIR besarbesaran di Perguruan Tinggi Indonesia sebagaimana grafik berikut ini:

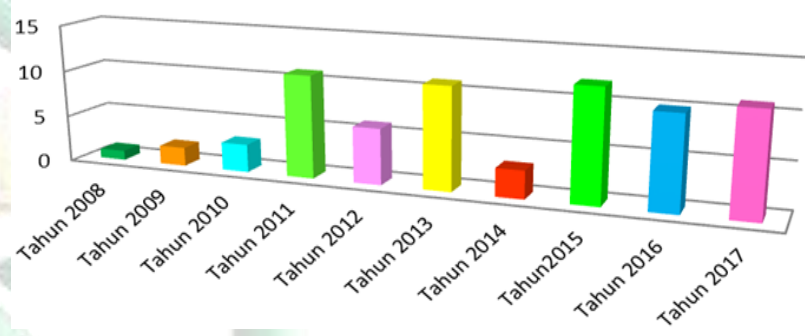

Grafik Jumlah instansi yang membangun repositori pertahun

Tingginya jumlah perguruan tinggi yang membangun OAIR pada tahun 2015 menjadi dasar bahwa pada tahun tersebut, banyak peraturan pemerintah terutama perundang-undangan yang membuat beberapa perguruan tinggi menggeliat untuk membuat para dosen dan professor untuk mempublikasikan penelitiannya ke dalam repositori.

Tingginya minat perguruan tinggi terhadap OAIR membuat komunikasi ilmiah antar perguruan tinggi semakin mudah. Akses temu balik informasi pun semakin cepat tanpa dibatasi ruang dan waktu terutama dalam mengakses skripsi, tesis, dan disertasi sebagain referensi kajian penelitian terdahulu dalam sebuah penelitian sebagai dasar menguatkan alasan suatu penelitian dilakukan. Tampak dari grafik berikut ini menggambarkan tingginya jumlah karya 
tulis ilmiah mahasiswa tingkat akhir yang paling banyak dilayankan melalui OAIR.

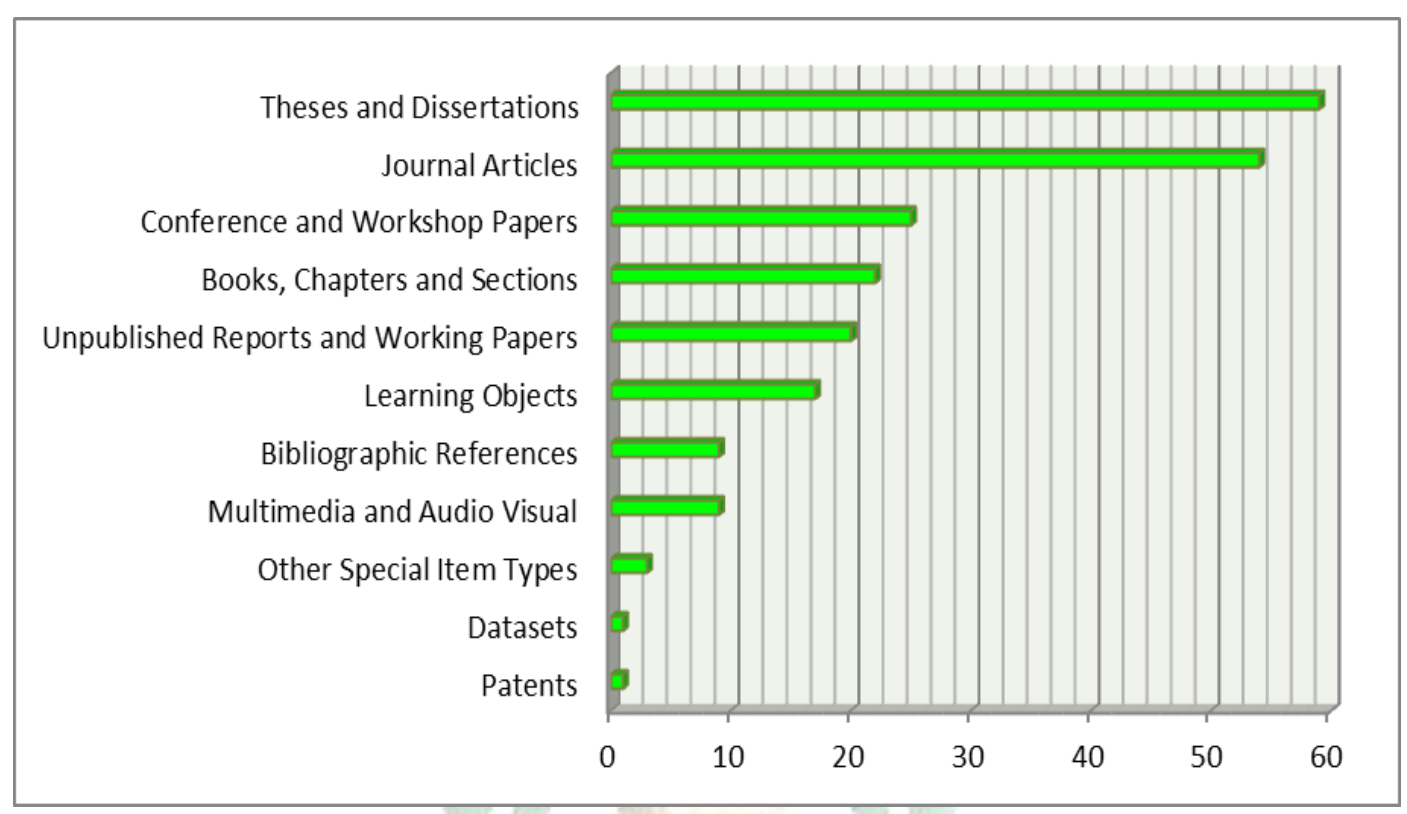

Grafik jumlah content OAIR di Perguruan Tinggi Indonesia

Pembangunan OAIR di $\ulcorner$ perguruan tinggi Indonesia tidak serta merta hanya mengedepankan kuantitas karya tulis ilmiah yang telah dialih mediakan, akan tetapi juga memperhatikan pentingnya penggunaan bahasa dalam penulisan karya tulis ilmiah maupun konsep layanan interface dalam memudahkan para civitas akademika setempat dalam menggunakan repositori.

\section{b. Pemetaan Perkembangan OAIR pada Perguruan Tinggi di Indonesia Berdasarkan Lokasi Geografis}

Perkembangan OAIR di beberapa wilayah yang ada di Indonesia sangat signifikan apabila dilihat dari tahun berdirinya OAIR tersebut. Namun dari segi jumlah OAIR setiap wilayah belum cukup merata secara universal. Adapun secara garis besar, jumlah repositori yang terdaftar di openDOAR adalah sebagai berikut:

\begin{tabular}{|c|c|c|}
\hline No & 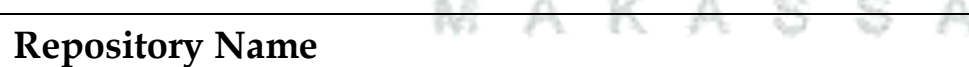 & Instansi \\
\hline 1 & Andalas University Repository & Universitas Andalas \\
\hline 2 & Binus University Repository & Binus University \\
\hline 3 & Borneo University Repository & Borneo University \\
\hline 4 & Digilib UIN Sunan Kalijaga & UIN Sunan Kalijaga Yogyakarta \\
\hline 5 & Digital Library of UIN Sunan Ampel & UIN Sunan Ampel Surabaya \\
\hline 6 & Digital Repository Universitas Negeri Medan & Universitas Negeri Medan \\
\hline 7 & EEPIS Repository & $\begin{array}{l}\text { Politeknik Elektronika Negeri } \\
\text { Surabaya }\end{array}$ \\
\hline 8 & ETD - Unsyiah Central Library & Syiah Kuala University \\
\hline 9 & $\begin{array}{l}\text { Etheses of Maulana Malik Ibrahim State Islamic } \\
\text { University (UIN) }\end{array}$ & UIN Maulana Malik Ibrahim \\
\hline 10 & ePrints Online Repository Sriwijaya University & Universitas Sriwijaya \\
\hline
\end{tabular}


Chusnul Chatimah Asmad, Taufiq Mathar, A. Khaidir Akbar, Nur Arifin, Hijrana, Haruddin, Irmawati, Irawati, Satriani: Tren perkembangan Open Access Institutional Repository pada Perguruan Tinggi di Indonesia

\begin{tabular}{|c|c|c|}
\hline 11 & eprints umsida & $\begin{array}{l}\text { Universitas Muhammadiyah } \\
\text { Sidoarjo }\end{array}$ \\
\hline 12 & Gunadarma University Repository & Gunadarma University \\
\hline 13 & Hasanuddin University Repository & Hasanuddin University \\
\hline 14 & IAIN Antasari Institutional Repository & IAIN Antasari Banjarmasin \\
\hline 15 & IAIN Sunan Ampel Repository & IAIN Sunan Ampel \\
\hline 16 & Bogor Agricultural University Repository & Bogor Agricultural University \\
\hline 17 & ISI Denpasar | Institutional Repository & Institut Seni Indonesia, Denpasar \\
\hline 18 & ITS Digital Repository & $\begin{array}{l}\text { Institut Teknologi Sepuluh } \\
\text { Nopember }\end{array}$ \\
\hline 19 & Indonesian Institute of the Art Yogyakarta & $\begin{array}{l}\text { Indonesian Institute of the Art } \\
\text { Yogyakarta }\end{array}$ \\
\hline 20 & $\begin{array}{l}\text { Institutional Repository UIN Syarif Hidayatullah } \\
\text { Jakarta }\end{array}$ & UIN Syarif Hidayatullah Jakarta \\
\hline 21 & Institutional Repository of IAIN Tulungagung & IAIN Tulungagung \\
\hline 22 & $\begin{array}{l}\text { Institutional Repository of Satya Wacana Christian } \\
\text { University }\end{array}$ & $\begin{array}{l}\text { Satya Wacana Christian } \\
\text { University }\end{array}$ \\
\hline 23 & Ispektra Digital Collection & Petra Christian University \\
\hline 24 & Lumbung Pustaka UNY (UNY Repository) & Yogyakarta State University \\
\hline 25 & MB IPB Repository & Bogor Agricultural University \\
\hline 26 & Musi Charitas Catholic University Repository & $\begin{array}{l}\text { Musi Charitas Catholic } \\
\text { University }\end{array}$ \\
\hline 27 & Neliti & Neliti \\
\hline 28 & POLNEP Repository & Politeknik Negeri Pontianak \\
\hline 29 & Pasundan Repository & Universitas Pasundan \\
\hline 30 & Portal Garuda STMIK IBBI (STMIK IBBI Repository) & STMIK IBBI \\
\hline 31 & $\begin{array}{l}\text { Repositori Institusi Kementerian Pendidikan dan } \\
\text { Kebudayaan }\end{array}$ & $\begin{array}{l}\text { Perpustakaan Kementerian } \\
\text { Pendidikan dan Kebudayaan }\end{array}$ \\
\hline 32 & Repositori Universitas Bhayangkara Jakarta Raya & $\begin{array}{l}\text { Universitas Bhayangkara Jakarta } \\
\text { Raya }\end{array}$ \\
\hline 33 & Repository Poltekkes Kemenkes Yogyakarta & Poltekkes Kemenkes Yogyakarta \\
\hline 34 & Repository ST3 Telkom & $\begin{array}{l}\text { Sekolah Tinggi Teknologi } \\
\text { Telematika Telkom Purwokerto }\end{array}$ \\
\hline 35 & Repository Universitas Sanata Dharma & Universitas Sanata Dharma \\
\hline 36 & Repository Universitas Padjadjaran & CISRAL Universitas Padjadjaran \\
\hline 37 & Repository Universitas PGRI Yogyakarta & Universitas PGRI Yogyakarta \\
\hline 38 & Repository Universitas Negeri Makassar & Universitas Negeri Makassar \\
\hline 39 & Repository Universitas Medan Area & Universitas Medan Area \\
\hline 40 & Repository UMMI & $\begin{array}{l}\text { University of Muhammadiyah } \\
\text { Sukabumi }\end{array}$ \\
\hline 41 & Repository UMM & $\begin{array}{l}\text { University of Muhammadiyah } \\
\text { Malang }\end{array}$ \\
\hline 42 & Repository UIN Sumatera Utara & $\begin{array}{l}\text { Universitas Islam Negeri } \\
\text { Sumatera Utara }\end{array}$ \\
\hline 43 & STIESIA Institutional Repository & $\begin{array}{l}\text { Sekolah Tinggi Ilmu Ekonomi } \\
\text { Indonesia (STIESIA) Surabaya }\end{array}$ \\
\hline 44 & STMIK GI MDP & STMIK GI MDP \\
\hline 45 & School of Business IPB Repository & Bogor Agricultural University \\
\hline
\end{tabular}




\begin{tabular}{lll}
\hline 46 & Scientific Repository & Petra Christian University \\
\hline 47 & Sistem Informasi Tugas Akhir & Universitas Kristen Duta \\
Wacana
\end{tabular}

Meskipun jumlahnya sudah bertambah yaitu 70 OAIR, namun terdapat dua IR yang tidak menjadi objek kajian penelitian tersebut dikarenakan satu diantaranya bukan merupakan perguruan tinggi melainkan lembaga informasi yang bergerak mengindeks seluruh jurnal yang Open Access di Indonesia, dan satu repositori yang merupakan milik pemerintah yaitu Kementerian Pendidikan dan Kebudayaan. Sehingga jumlah repositori yang ada yaitu hanya 68 IR ditinjau dari perguruan tinggi yang menerbitkan.

Adapun dari segi geografis, Surabaya merupakan wilayah yang paling banyak membangun OAIR di perguruan Tinggi. Sebagaimana grafik di bawah ini: 


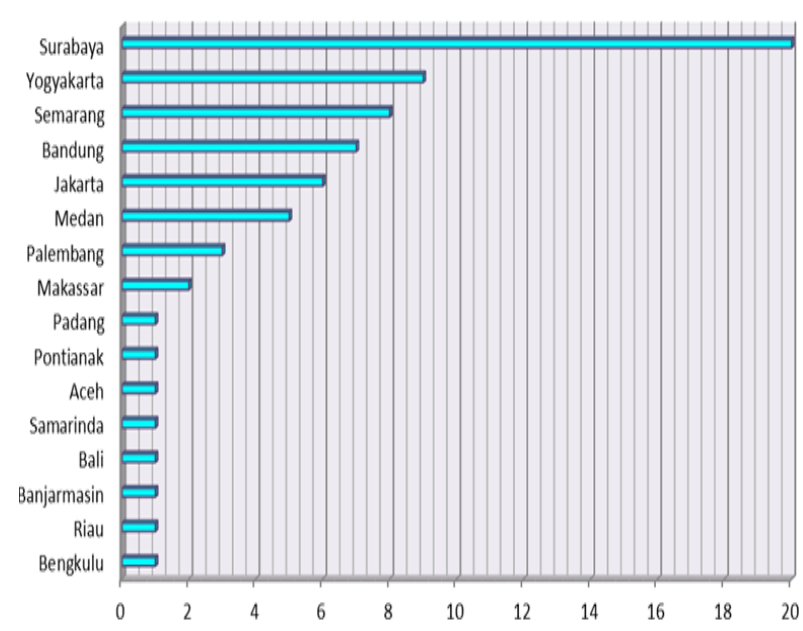

Selanjutnya kota pendidikan Yogyakarta menyusul dengan range yang tidak berimbang dari jumlah repositori yang ada di Surabaya yang berkisar sebanyak 20 IR, sementara Yogyakarta hanya 9 IR. Yogyakarta dan Bandung beriringan dalam jumlah OAIR di mana terdapat sebanyak 8 IR di Bandung yang saat ini telah terdaftar di OpenDOAR. Sementara Padang, Pontianak, Aceh, Samarinda, Bengkulu, Bali, Riau, dan Banjarmasin hanya terdapat masingmasing satu institusi yang membangun repositori. Berdasarkan grafik tersebut, maka dapat dinyatakan bahwa Indonesia Bagian Barat merupakan wilayah geografis yang paling banyak membangun OAIR. Sementara Indonesia Bagian Tengah merupakan wilayah geografis yang lumayan banyak membangun repositori dengan Indonesia Bagian Timur merupakan wilayah yang paling sedikit membangun repositori. Hal demikian berarti bahwa, perlu adanya peningkatakan pemahaman akan pentingnya membangun OAIR di perguruan tinggi dan mendaftarkannya ke OpenDOAR terutama pada daerah Indonesia Bagian Timur.

\section{c. Pemetaan Perkembangan OAIR pada Perguruan Tinggi di Indonesia Berdasarkan Perangkat Lunak (software) yang Digunakan}

Pada tahun 2015, DSpace merupakan perangkat lunak yang paling banyak digunakan perguruan tinggi dalam membangun repositori. EPrints menjadi kategori kedua, namun hasil temuan tersebut merupakan representasi ROAR. Sementara berdasarkan statistik OpenDOAR khusus area Indonesia, EPrints merupakan perangkat lunak yang paling banyak digunakan di Indonesai sebagaimana grafik di bawah ini:

\section{Software Platforms Overview}

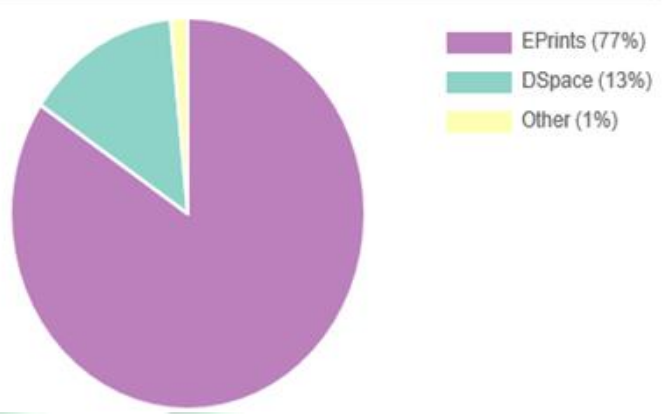

Berdasarkan Grafik di atas, maka dapat dinyatakan bahwa perangkat lunak EPrints merupakan software yang paling mudah digunakan dengan berbagai fitur dan interface yang user friendly. Namun pada wilayah Eropa, America, dan Asia secara umum, DSPace merupakan perangkat lunak yang paling banyak digunakan.

\section{KESIMPULAN}

Sejak tahun 2008 hingga 2018, jumlah repositori yang terdaftar di OpenDOAR sebanyak 69 entri. Hal ini masih sangat jauh dengan jumlah keseluruhan perguruan tinggi yang ada di Indonesia. Gerakan OA ini berarti belum merata secara universal di seluruh wilayah Indonesia khususnya Indonesia bagian tengah dan timur. Namun demikian peningkatannya dari tahun 2016 hingga 
2018 telah cukup signifikan meski grafiknya tidak bergerak secara horizontal. Penggunaan software EPrints juga menjadi alasan berkembangnya OAIR di Indonesia dikarenakan fiturnya yang user friendly. Keadaan OAIR Indonesia saat ini masih perlu ditingkatkan demi melancarkan alur temu balik informasi di seluruh perguruan tinggi, menghidupkan komunikasi ilmiah antar civitas akademik, dan sebagai benchmarking untuk setiap perguruan tinggi yang ada.

\section{DAFTAR PUSTAKA}

American Library Association. (2012). “The 2012 State of America's Libraries: A Report from The American Library Association."

Barton, M. R., \& Waters, M. M. (2004). Creating an institutional repository: LEADIRS workbook. Boston, MA: MIT Libraries. Retrieved from http:/ / dspace.mit.edu/bitstream/han dle/1721.1/26698/Barton_2004_Creati ng.pdf?sequence $=1$

Cullen, R, and Brenda C. 2011. "Institutional Repositories, Open Access, and Scholarly Communication: A Study of Conflicting Paradigms." Journal of Academic Librarianship 37 (6). Elsevier Inc.: 460-70. https://doi.org/10.1016/j.acalib.2011. 07.002 .

Das, K. C., \& Singh, K. (2017). Current Status of Chinese Open Access Institutional Repositories: A Case Study. International Research: Journal of Library \& Information Science, 7(1), 62-71.

Farida, I., Tjakraatmadja, J. H., Firman, A., \& Basuki, S. (2015). A conceptual model of Open Access Institutional Repository in Indonesia academic libraries: Viewed from knowledge management perspective. Library
Management, 36(1/2), 168-181. https://doi.org/10.1108/LM-03-20140038

Ghosh, S. B., \& Kumar Das, A. (2007). Open Access and Institutional Repositories - A Developing Country Perspective: A case study of India. IFLA Journal, 33(3), 229-250. https://doi.org/10.1177/03400352070 83304

Islam, M. A., \& Akter, R. (2013). Institutional Repositories and Open Access Initiatives in Bangladesh: A New Paradigm of Scholarly Communication. LIBER Quarterly, 23(1), 3-24. https://doi.org/http:/ / doi.org/10.18 352/lq.8245

Jain, P. (2011). New trends and future applications/directions of institutional repositories in academic institutions. Library Review, 60(2), 125-141.

https://doi.org/10.1108/00242531111 113078

Kementerian Ristekdikti (2018). Rekap Pelaporan PDDIKTI. Retrieved from https://forlap.ristekdikti.go.id/pergu ruantinggi/homerekap/NTM1QzA4 QzYtNzMyMS00RjdFLThCMzktQ0E1 NzdDOTk3MDRF/0

Leng, C. B., Ali, K. M., \& Hoo, C. E. (2016). Open Access repositories on open educational resources. Asian Association of Open Universities Journal, 11(1), 35-49. https://doi.org/10.1108/AAOUJ-062016-0005

Lynch, C. A. (2003). Institutional Repositories: Essential Infrastructure for Scholarship in the Digital Age. ARL. Retrieved from http://www.arl.org/resources/pubs /br/br226/br226ir.shtml.

Narayan, B., \& Luca, E. (2017). Issues and challenges in researchers' adoption of Open Access and institutional 
repositories: a contextual study of a university repository. In Proceedings of RAILS - Research Applications, Information and Library Studies (pp. 6-8). New Zealand: School of Information Management, Victoria University of Wellington. Retrieved from http://informationr.net/ir/224/rails/rails1608.html

Okoye, M. ., \& Ejikeme, A. . (2011). Open Access, Institutional Repositories, and Scholarly Publishing: The Role of Librarians in South Eastern Nigeria Open Access , Institutional Repositories , and Scholarly Publishing: The Role of Librarians in South Eastern. Library Philosophy and Practice, 2011(2004), 1-9.

OpenDOAR. (2013). Directory of Open Access repositories. Retrieved from http://www.opendoar.org/onechart. php

Zhong, J., \& Jiang, S. (2016). Institutional Repositories in Chinese Open Access Development: Status, Progress, and Challenges. Journal of Academic Librarianship, 42(6), 739-744. https://doi.org/10.1016/j.acalib.2016. 06.015

Zaki, F. M, and Wan Ab. Kadir Wan Dollah. 2012. "Current Status of Open Access Institutional Repository: A Case Study in Universiti Teknologi Mara (UiTM)." Journal of Emerging Trends in Computing and Information Sciences 3 (3): 427-31. http:/ /www.doaj.org/doaj?func=ope nurl $\&$ issn $=20798407 \&$ date $=2012 \&$ volu me $=3 \&$ issue $=3 \&$ spage $=427 \&$ genre $=$ art icle.

Yiotis, K. 2005. “The Open Access Initiative: A New Paradigm for Scholarly Communications." Information Technology and Libraries 24 (4): 157. https://doi.org/10.6017/ital.v24i4.33 78. 